Navigation Physics 2(2)(2020)
Navigation Physics
Journal of Physics Education

\title{
Alat Bantu Prediksi Kecepatan pada Gerak Lurus Berubah Beraturan Menggunakan Metode Interpolasi Berdimensi Satu
}

\author{
Nurullaeli \\ Universitas Indraprasta PGRI Jakarta \\ E-mail: leli.biofisika@gmail.com
}

\begin{tabular}{|c|c|}
\hline Info Artikel & Abstract \\
\hline $\begin{array}{l}\text { Sejarah Artikel: } \\
\text { Diterima November } 2020 \\
\text { Disetujui Desember } 2020 \\
\text { Dipublikasikan Desember } 2020\end{array}$ & $\begin{array}{l}\text { The purpose of this study is to create a speed prediction tool in a uniformly } \\
\text { accelerated linear motion using a single-dimensional interpolation method } \\
\text { consisting of linear, cubic, cubic spline, and nearest neighbor interpolation } \\
\text { methods. This tool is packaged in the form of Graphic User Interface } \\
\text { (GUI) using Matlab programming language. This tool can be used as a } \\
\text { medium of the analysis of the object speed experiencing a uniformly } \\
\text { accelerated linear motion and a combination of several uniformly } \\
\text { accelerated linear motions. Speed prediction results using linear, cubic, and } \\
\text { cubic spline interpolation methods do not differ much from the results of } \\
\text { analytical calculations, while speed prediction results using nearest } \\
\text { neighbor interpolation method are less in line with the results of analytical } \\
\text { calculations because nearest neighbor interpolation method will generate } \\
\text { constant values around the data point. This tool can also be used as a } \\
\text { learning medium to make it easier for students to learn the concept of } \\
\text { uniformly accelerated linear motion in order to reduce the misconceptions } \\
\text { in the material. }\end{array}$ \\
\hline
\end{tabular}

How to Cite: Nurullaeli, N. (2020). Alat Bantu Prediksi Kecepatan pada Gerak Lurus Berubah Beraturan Menggunakan Metode Interpolasi Berdimensi Satu. Navigation Physics, 2 (2): 47-54.

\section{PENDAHULUAN}

Ilmu fisika dapat digunakan untuk mempelajari berbagai fenomena alam, salah satunya yaitu Gerak Lurus Berubah Beraturan (GLBB). Gerak ini merupakan salah satu pokok bahasan pada materi kinematika. GLBB adalah gerak yang lintasannya berupa garis lurus dengan kecepatannya yang berubahubah secara teratur dan memiliki percepatan yang konstan (Prihatini, 2017: 20). Analisis mengenai kecepatan benda pada GLBB dapat dilakukan dengan perhitungan matematik dan melalui pembacaan grafik yang merepresentasikan gerak tersebut. Analisis ini akan cukup rumit ketika dihadapkan pada data atau grafik kombinasi GLBB, sehingga dibutuhkan kemampuan perhitungan dan pembacaan grafik yang baik. Masih banyak mahasiswa yang mengalami miskonsepsi ketika menjawab soal dalam bentuk grafik kecepatan terhadap waktu (Busyairi dan Zuhdi, 2020: 93).

Metode numerik dapat digunakan sebagai penunjang dalam proses belajar mengajar. Saat ini metode numerik banyak digunakan dalam berbagai disiplin ilmu, tidak terkecuali dalam ilmu fisika. Metode numerik digunakan untuk mempermudah mendapatkan solusi persamaan yang sulit diselesaikan secara analitik atau bahkan persamaan yang tidak dapat diselesaikan secara analitik (Nurullaeli, 2020: 1). Salah satu metode numerik yang dapat dipakai dalam analisis kecepatan pada GLBB adalah metode interpolasi. Metode interpolasi dapat digunakan untuk memprediksi titik-titik data baru pada rentang data yang awalnya sudah diketahui. Menurut Herlinawati (2019: 65), interpolasi adalah pencarian fungsi $\mathrm{F}: \mathrm{X} \rightarrow \mathrm{R}$ yang melalui sejumlah titik data yang diberikan.

Alternatif alat bantu analisis kecepatan pada GLBB yang dilengkapi dengan grafik diperlukan agar mahasiswa dapat lebih mudah mempelajari konsep GLBB sehingga mengurangi adanya miskonsepsi dalam materi tersebut. Alat bantu ini juga diperlukan mahasiswa ketika dalam proses pengambilan data mengenai GLBB tidak memungkinkan mengambil semua data atau ada kehilangan data dan tidak 
memungkinkan apabila pengambilan data tersebut harus diulangi lagi. Dalam penelitian ini, peneliti membuat GUI yang dapat digunakan sebagai alat bantu prediksi kecepatan pada GLBB dengan menggunakan metode interpolasi linear, cubic, cubic spline, dan nearest neighbor. Pada umumnya proses interpolasi berhubungan dengan banyak data sehingga lebih mudah jika dalam perhitungan digunakan software penunjang. Peneliti memilih menggunakan software Matlab karena menyediakan fungsi panggilan untuk interpolasi dan terdapat fasilitas untuk membuat GUI yang friendly.

\section{METODE PENELITIAN}

Penelitian ini dibagi menjadi tiga tahap, yaitu studi pustaka, analisis numerik data GLBB, dan analisis sistem fisis.

\section{A. Studi Pustaka}

Tahapan ini dilakukan untuk memahami lebih dalam mengenai konsep GLBB dan metode interpolasi data berdimensi satu yang terdiri dari interpolasi linear, interpolasi cubic, interpolasi cubic spline, serta interpolasi nearest neighbor. Selain itu, tahapan ini juga dilakukan untuk mengetahui sejauh mana perkembangan dari bidang yang diteliti.

\section{B. Analisis Numerik}

Analisis numerik digunakan untuk memprediksi kecepatan benda pada GLBB dari rentang data yang sudah diketahui sebelumnya dengan memanfaatkan metode interpolasi data berdimensi satu. Analisis numerik pada data GLBB tersebut dikemas dalam bentuk GUI menggunakan software Matlab R2013a. Beberapa metode interpolasi data berdimensi satu yang digunakan dalam analisis numerik ini, yaitu:

1. Interpolasi Linear

Interpolasi linear adalah teknik interpolasi paling sederhana dengan cara menghubungkan dua titik dengan garis lurus. Formula untuk interpolasi linear, yaitu sebagai berikut:

$f_{1}(x)=f\left(x_{0}\right)+\frac{f\left(x_{1}\right)-f\left(x_{0}\right)}{x_{1}-x_{0}}\left(x-x_{0}\right)$

Notasi $f_{l}(x)$ menunjukkan bahwa ini adalah polinomial interpolasi orde pertama. Secara umum, semakin kecil intervalnya antara titik data, semakin baik perkiraannya. Hal ini disebabkan oleh fakta bahwa, dengan berkurangnya interval, fungsi kontinu akan lebih baik didekati dengan garis lurus (Chapra dan Canale, 2010: 489-490). Algoritma interpolasi linear, yaitu:

a. Menentukan dua titik awal disekitar titik yang akan ditentukan dengan koordinat masingmasing $\left(x_{0}, f\left(x_{0}\right)\right)$ dan $\left(x_{1}, f\left(x_{1}\right)\right)$.

b. Menentukan titik $x$ dari titik yang akan dicari.

c. Menghitung nilai $f_{l}(x)$ menggunakan persamaan (1).

d. Menampilkan nilai titik yang dicari.

2. Interpolasi Cubic

Interpolasi cubic sama dengan interpolasi linear, yaitu merupakan bagian dari interpolasi beda terbagi newton. Interpolasi ini merupakan interpolasi orde tiga dimana membutuhkan empat titik data untuk menentukan satu data prediksi. Formula untuk interpolasi cubic, yaitu sebagai berikut:

$f_{3}(x)=b_{0}+b_{1}\left(x-x_{0}\right)+b_{2}\left(x-x_{0}\right)\left(x-x_{1}\right)+b_{3}\left(x-x_{0}\right)\left(x-x_{1}\right)\left(x-x_{2}\right)$

dimana

$b_{n}=f\left[x_{n}, x_{n-1}, \ldots ., x_{1}, x_{0}\right]$

$f\left[x_{n}, x_{n-1}, \ldots . ., x_{1}, x_{0}\right]=\frac{f\left[x_{n}, x_{n-1}, \ldots . . x_{1}\right]-f\left[x_{n-1}, x_{n-2}, \ldots, x_{0}\right]}{x_{n}-x_{0}}$

(Chapra dan Canale, 2010: 493-494). Algoritma interpolasi cubic, yaitu:

a. Menentukan empat titik data disekitar titik yang akan ditentukan dengan koordinat masingmasing $\left(x_{0}, f\left(x_{0}\right)\right),\left(x_{1}, f\left(x_{1}\right)\right),\left(x_{2}, f\left(x_{2}\right)\right)$, dan $\left(x_{3}, f\left(x_{3}\right)\right)$.

b. Menentukan titik $x$ dari titik yang akan dicari.

c. Menghitung nilai $f_{3}(x)$ menggunakan persamaan (2), (3) dan (4).

d. Menampilkan nilai titik yang dicari.

3. Interpolasi Cubic Spline

Tujuan dalam cubic spline adalah untuk mendapatkan polinomial orde tiga untuk setiap interval antara titik-titik data, seperti pada 
$f_{i}(x)=a_{i} x^{3}+b_{i} x^{2}+c_{i} x+d_{i}$

Jadi, untuk $n+1$ titik data $(i=0,1,2, \ldots, n)$, terdapat $n$ interval sehingga terdapat $4 n$ konstanta yang harus dievaluasi (Chapra dan Canale, 2010: 515). Interpolasi cubic spline ini lebih disukai karena menyediakan representasi paling sederhana yang menunjukkan tampilan (lebih halus) yang diinginkan (Chapra, 2012: 438). Algoritma interpolasi cubic spline, yaitu:

a. Membuat sistem persamaan linear untuk menghitung turunan $f$ kedua.

b. Mencari selang yang relevan terhadap titik interpolasi yang diinginkan.

c. Menghitung nilai $f$ ketika titik interpolasi terdapat di antara subselang tersebut merupakan subselang ke- $n$.

4. Interpolasi Nearest Neighbor

Metode ini menetapkan nilai titik interpolasi ke nilai titik data terdekat yang ada. Jadi, interpolasi tampak seperti serangkaian dataran tinggi yang dapat dianggap sebagai polinomial orde-nol (Chapra, 2012: 446).

Matlab dapat digunakan untuk menginterpolasi set titik data diskrit menggunakan interpolasi nearest neighbor, interpolasi linear, interpolasi cubic spline, atau interpolasi cubic ( Burden dan Faires, 2011: 172).

\section{Analisis Sistem Fisis}

Tahapan ini dilakukan dengan menganalisis sistem fisis dari hasil prediksi kecepatan dan grafik waktu terhadap kecepatan pada tampilan GUI yang dibuat.

\section{HASIL DAN PEMBAHASAN}

Alat bantu prediksi kecepatan pada GLBB yang dibuat peneliti dikemas dalam bentuk GUI dengan lima jendela. Jendela pertama merupakan jendela halaman awal dan keempat jendela yang lain merupakan jendela untuk prediksi kecepatan pada GLBB dengan metode interpolasi berdimensi satu. Setiap jendela dilengkapi dengan menu editor dibagian atas. Menu editor tersebut yaitu berupa menu halaman awal, menu metode prediksi, dan menu keluar. Pada menu metode prediksi, pengguna dapat memilih metode interpolasi yang akan dipakai, yaitu metode interpolasi linear, interpolasi cubic, interpolasi cubic spline, dan interpolasi nearest neighbor. Tampilan jendela halaman awal dapat dilihat pada gambar 1.

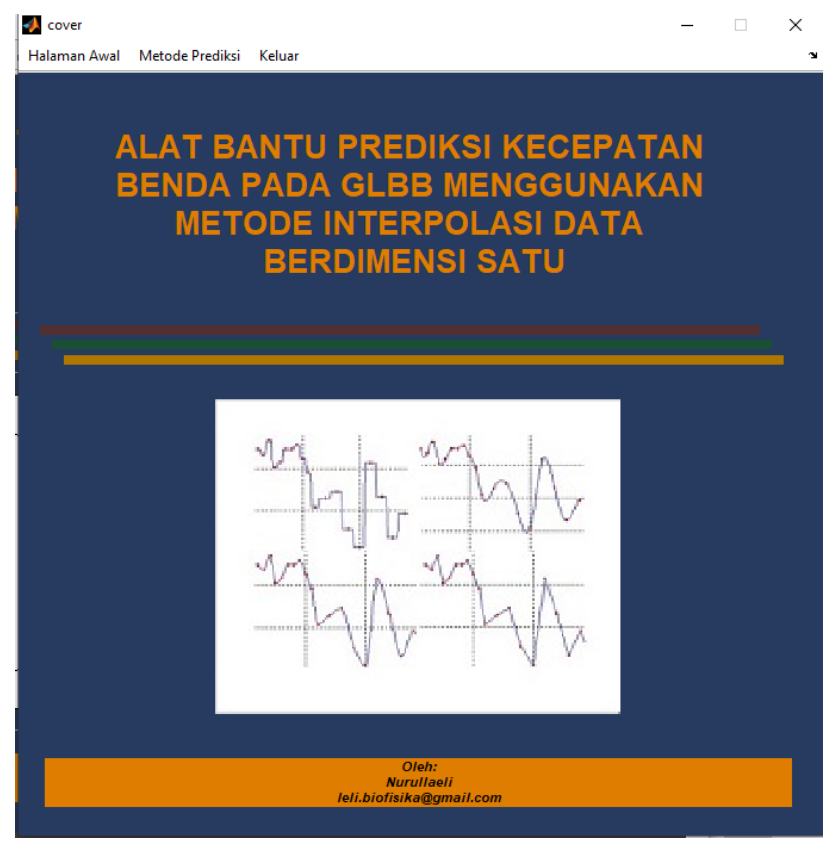

Gambar 1. Tampilan Jendela Halaman Awal Sumber: Peneliti

Data awal yang berisi data waktu dan kecepatan GLBB disimpan dalam notepad dengan nama datatv.txt. Pada kali ini akan dipakai data kombinasi GLBB. Contoh penulisan data dalam notepad dapat dilihat pada gambar 2 . 


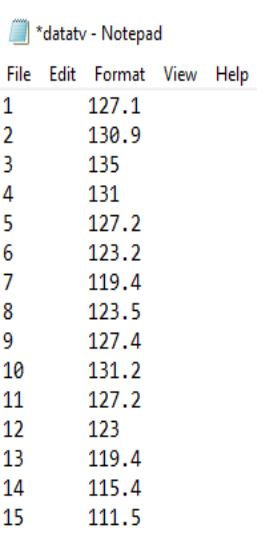

Gambar 2. Data Waktu dan Kecepatan GLBB Sumber: Peneliti

Pengguna dapat memulai analisis data dengan memilih metode prediksi pada menu editor, kemudian memasukkan data dengan menekan tombol Masukkan Data dan memilih file datatv.txt. Untuk proses perhitungan, langkah pertama pengguna harus memasukkan step waktu (selisih antar waktu yang diinginkan) dan waktu dimana saat kecepatannya akan dicari, kemudian menekan tombol HITUNG. Jika data awal dan data prediksi kecepatan akan disimpan, pengguna dapat menekan tombol SIMPAN DATA. Data tersebut akan tersimpan dalam format .txt. Pengguna juga dapat mencari kecepatan pada saat waktu lainnya dengan cara menekan tombol RESET, kemudian memasukkan nilai untuk step waktu dan waktu dimana saat kecepatannya akan dicari. Output dari alat bantu ini berupa data kecepatan dan grafik waktu terhadap kecepatan. Prediksi kecepatan menggunakan interpolasi linear dapat dilihat pada gambar 3 dan data hasil interpolasi linear dalam format txt dapat dilihat pada gambar 4. Hasil prediksi kecepatan untuk data gambar 2 dengan metode interpolasi linear dengan step waktu 0.25 jam pada waktu 5.25 jam, yaitu $126.2 \mathrm{~km} / \mathrm{jam}$.

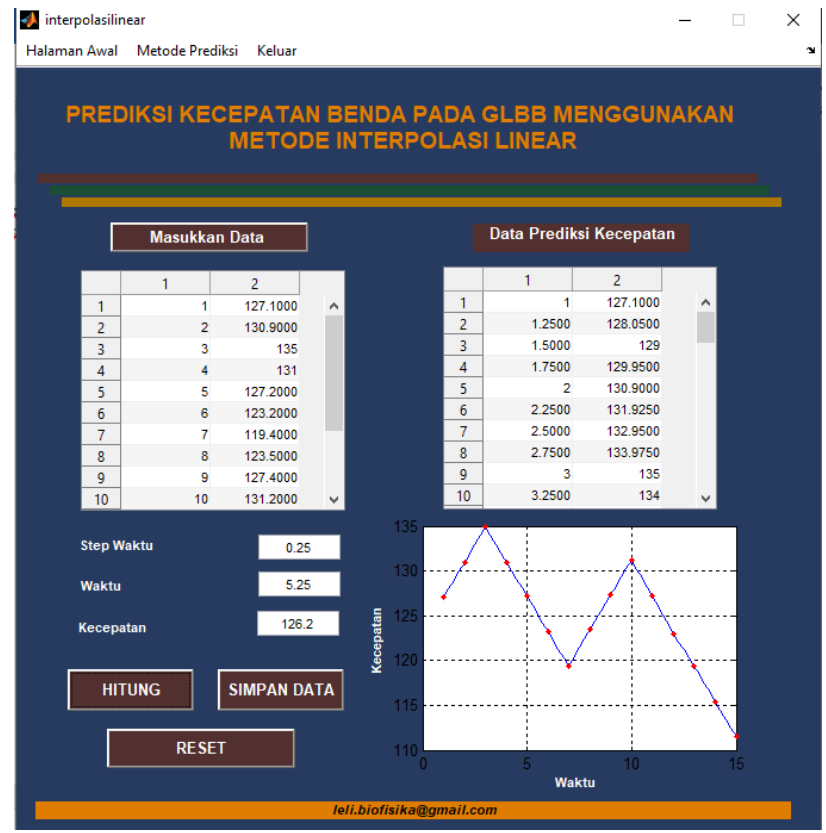

Gambar 3. Tampilan Jendela Prediksi Kecepatan Benda pada GLBB Menggunakan Metode Interpolasi Linear Sumber: Peneliti 


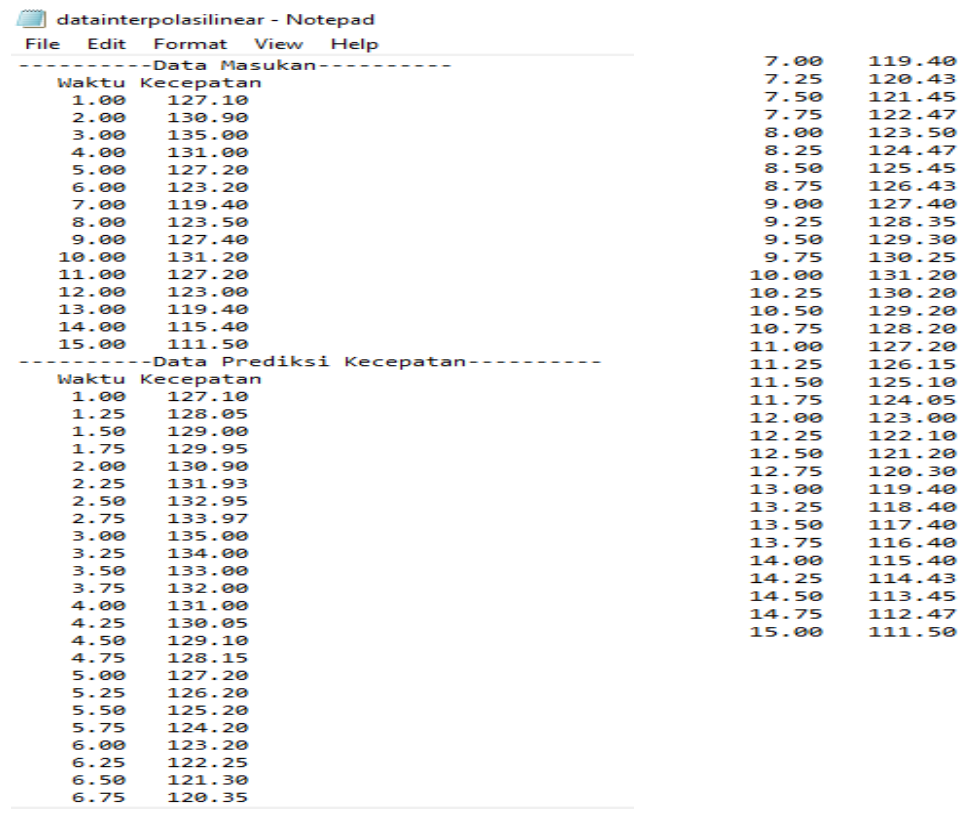

Gambar 4. Data Hasil Interpolasi Linear Sumber: Peneliti

Metode prediksi kedua, yaitu metode interpolasi cubic. Ketika dilakukan interpolasi cubic pada data di gambar 2 dengan step waktu 0.25 jam pada waktu 5.25 jam didapatkan nilai kecepatan yang tidak berbeda jauh dengan hasil interpolasi linear, yaitu $126.2096 \mathrm{~km} / \mathrm{jam}$. Tampilan jendela prediksi kecepatan menggunakan metode interpolasi cubic dapat dilihat pada gambar 5.

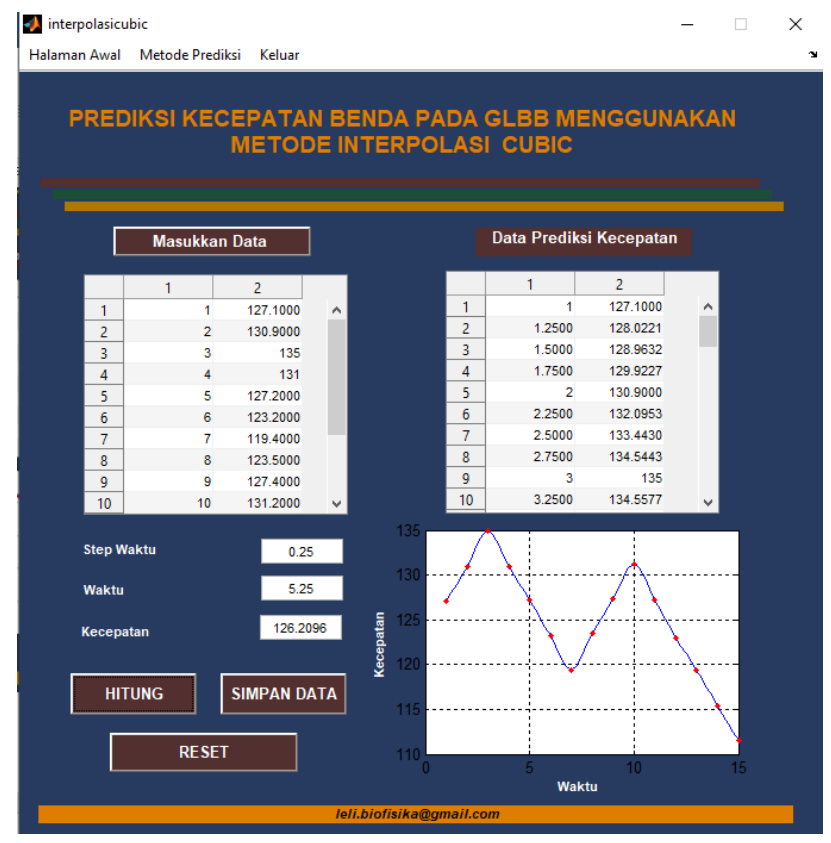

Gambar 5. Tampilan Jendela Prediksi Kecepatan Benda pada GLBB Menggunakan Metode Interpolasi Cubic Sumber: Peneliti

Hasil prediksi kecepatan untuk data gambar 2 menggunakan metode ketiga, yaitu metode interpolasi cubic spline dengan step waktu 0.25 jam pada waktu 5.25 jam hampir sama dengan metode interpolasi linear dan cubic. Hasil prediksi kecepatan dengan metode interpolasi cubic spline tersebut sebesar $126.3443 \mathrm{~km} / \mathrm{jam}$. Tampilan jendela prediksi kecepatan menggunakan metode interpolasi cubic spline dapat dilihat pada gambar 6. 


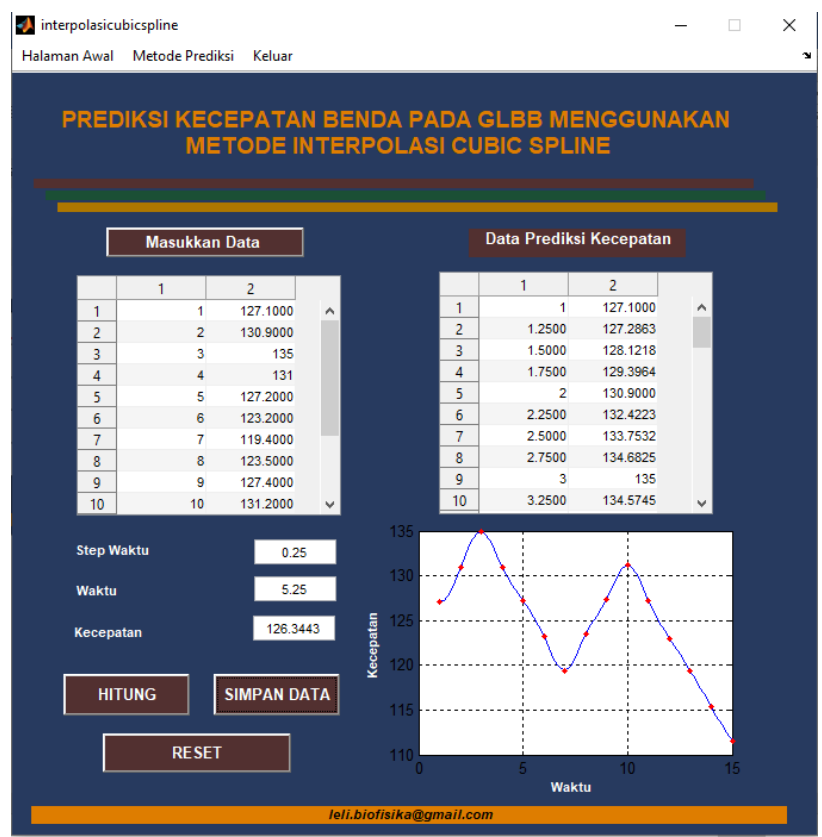

Gambar 6. Tampilan Jendela Prediksi Kecepatan Benda pada GLBB Menggunakan Metode Interpolasi Cubic Spline Sumber: Peneliti

Sedangkan hasil prediksi kecepatan untuk data gambar 2 menggunakan metode keempat, yaitu metode interpolasi nearest neighbor dengan step waktu $0.25 \mathrm{jam}$ pada waktu $5.25 \mathrm{jam}$, yaitu $127.2 \mathrm{~km} / \mathrm{jam}$. Nilai kecepatan ini sama dengan kecepatan saat waktu 5 jam, karena metode interpolasi nearest neighbor akan menghasilkan nilai konstan di sekitar titik data. Dari hasil yang diperoleh dapat dilihat bahwa interpolasi nearest neighbor tidak cocok digunakan untuk data GLBB. Tampilan jendela prediksi kecepatan menggunakan metode interpolasi nearest neighbor dapat dilihat pada gambar 7 .

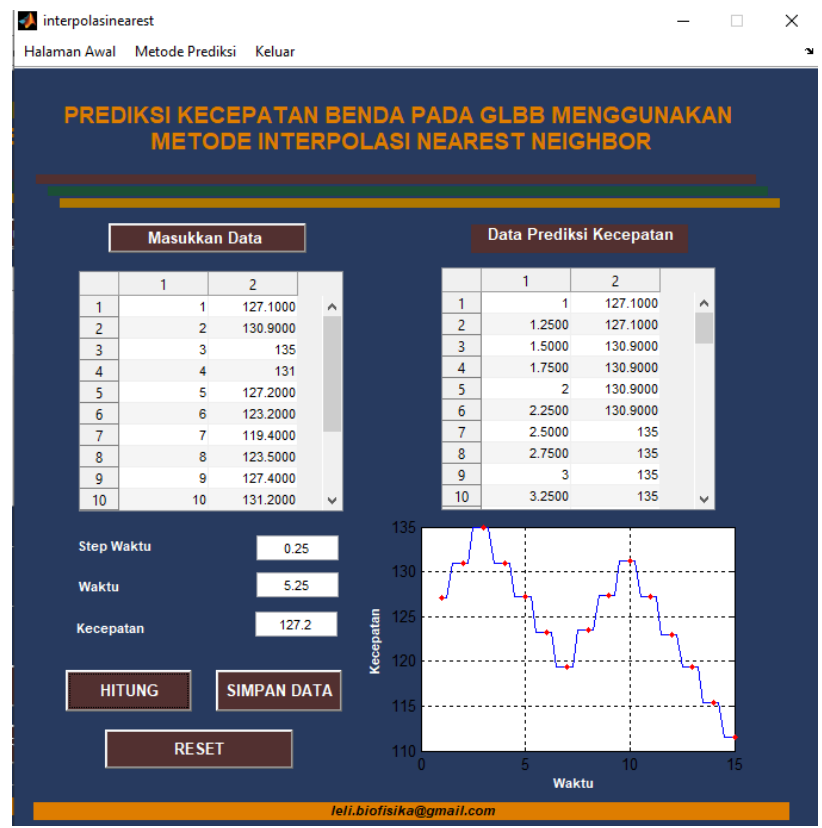

Gambar 7. Tampilan Jendela Prediksi Kecepatan Benda pada GLBB Menggunakan Metode Interpolasi Nearest Neighbor Sumber: Peneliti

Data pada gambar 2 merupakan data kombinasi GLBB dipercepat dan diperlambat. Jika dilakukan perhitungan kecepatan pada beberapa titik sepanjang data secara analitik akan cukup rumit dan membutuhkan waktu cukup lama karena analisis harus dilakukan sesuai segmen geraknya. Untuk menentukan prediksi kecepatan pada setiap segmen gerak harus ditentukan terlebih dahulu kecepatan 
awal, kecepatan akhir, percepatan, dan waktu titik saat kecepatan akan diprediksi dihitung dari titik saat kecepatan awal diambil. Kecepatan benda saat waktu 5.25 jam dengan perhitungan analitik, yaitu sebagai berikut:

$$
\begin{aligned}
& a=\frac{v_{7}-v_{3}}{t_{7}-t_{3}}=\frac{119.4-135}{7-3}=-3.9 \mathrm{~km} / \mathrm{jam}^{2} \\
& v_{5.25}=v_{3}+a t_{5.25-3}=135+(-3.9)(5.25-3)=126.225 \mathrm{~km} / \mathrm{jam}
\end{aligned}
$$

Hasil dari perhitungan analitik tidak berbeda jauh dengan hasil prediksi kecepatan menggunakan metode interpolasi linear, cubic, dan cubic spline.

Untuk hasil perhitungan prediksi kecepatan kombinasi GLBB (data pada gambar 2) dengan metode interpolasi dan analitik di beberapa titik dapat dilihat pada tabel 1. Pada umumnya hasil interpolasi cubic spline akan lebih baik dari pada metode interpolasi cubic dan interpolasi linear, tetapi ketiga metode ini tidak jauh berbeda ketika dipakai untuk data GLBB tersebut karena sebaran data cenderung teratur. Metode nearest neighbor kurang sesuai dipakai untuk prediksi kecepatan GLBB dikarenakan metode interpolasi nearest neighbor akan menghasilkan nilai konstan di sekitar titik data. Jika dibandingkan dari beberapa metode interpolasi yang dipakai, interpolasi linear di beberapa titik prediksi mempunyai persentase kesalahan yang lebih kecil dikarenakan metode interpolasi linear baik digunakan untuk data yang benar-benar membentuk garis lurus.

Tabel 1. Hasil Perhitungan dengan Metode Interpolasi dan Analitik

\begin{tabular}{cccccccccc}
\hline \multirow{2}{*}{$\begin{array}{c}\text { Waktu } \\
\text { (jam) }\end{array}$} & \multicolumn{4}{c}{ Linear } & Cubic & $\begin{array}{c}\text { Cubic } \\
\text { Spline }\end{array}$ & $\begin{array}{c}\text { Nearest } \\
\text { Neighbor }\end{array}$ & $\begin{array}{c}\text { Perhitungan } \\
\text { Analitik } \\
(\mathrm{km} / \mathrm{jam})\end{array}$ & \multicolumn{4}{c}{ Linear } & Cubic & $\begin{array}{c}\text { Cubic } \\
\text { Spline }\end{array}$ & $\begin{array}{c}\text { Nearest } \\
\text { Neighbor }\end{array}$ \\
\hline $\mathbf{1 . 0 0}$ & $\mathbf{1 2 7 . 1 0}$ & $\mathbf{1 2 7 . 1 0}$ & $\mathbf{1 2 7 . 1 0}$ & $\mathbf{1 2 7 . 1 0}$ & & & & & \\
1.25 & 128.05 & 128.02 & 127.29 & 127.10 & 128.09 & 0.03 & 0.05 & 0.62 & 0.77 \\
1.50 & 129.00 & 128.96 & 128.12 & 130.90 & 129.08 & 0.06 & 0.09 & 0.74 & 1.41 \\
1.75 & 129.95 & 129.92 & 129.40 & 130.90 & 130.06 & 0.09 & 0.11 & 0.51 & 0.64 \\
$\mathbf{2 . 0 0}$ & $\mathbf{1 3 0 . 9 0}$ & $\mathbf{1 3 0 . 9 0}$ & $\mathbf{1 3 0 . 9 0}$ & $\mathbf{1 3 0 . 9 0}$ & & & & & \\
2.25 & 131.93 & 132.09 & 132.42 & 130.90 & 132.04 & 0.08 & 0.04 & 0.29 & 0.86 \\
2.50 & 132.95 & 133.44 & 133.75 & 135.00 & 133.03 & 0.06 & 0.31 & 0.55 & 1.48 \\
2.75 & 133.97 & 134.54 & 134.68 & 135.00 & 134.01 & 0.03 & 0.39 & 0.50 & 0.74 \\
$\mathbf{3 . 0 0}$ & $\mathbf{1 3 5 . 0 0}$ & $\mathbf{1 3 5 . 0 0}$ & $\mathbf{1 3 5 . 0 0}$ & $\mathbf{1 3 5 . 0 0}$ & & & & & \\
3.25 & 134.00 & 134.56 & 134.57 & 135.00 & 134.03 & 0.02 & 0.40 & 0.41 & 0.73 \\
\hline
\end{tabular}

Sumber: Peneliti

\section{PENUTUP}

Alat bantu prediksi kecepatan yang dibuat dapat digunakan sebagai media analisis kecepatan benda yang mengalami GLBB maupun kombinasi dari beberapa GLBB. Hasil prediksi kecepatan menggunakan metode interpolasi linear, cubic, dan cubic spline tidak berbeda jauh dengan hasil perhitungan analitik, sedangkan hasil prediksi kecepatan menggunakan metode interpolasi nearest neighbor kurang sesuai dengan hasil perhitungan analitik karena metode interpolasi nearest neighbor akan menghasilkan nilai konstan di sekitar titik data. Pada umumnya hasil interpolasi cubic spline akan lebih baik dari pada metode interpolasi cubic dan interpolasi linear, tetapi ketiga metode ini tidak jauh berbeda ketika dipakai untuk data GLBB karena pada gerak tersebut sebaran data cenderung teratur. Alat bantu ini juga dapat digunakan sebagai media pembelajaran agar mahasiswa lebih mudah mempelajari konsep GLBB sehingga mengurangi adanya miskonsepsi dalam materi tersebut.

Adapun saran untuk penelitian selanjutnya, yaitu dalam prediksi kecepatan GLBB tidak perlu menggunakan metode interpolasi nearest neighbor. Dalam pengembangan penelitian perlu adanya variasi gerak yang dianalisis dan adanya penambahan perhitungan besaran lain yang terkait dengan gerak. Selain itu, tampilan GUI dapat dibuat lebih menarik dengan tambahan simulasi gerak yang sedang dianalisis. 


\section{DAFTAR PUSTAKA}

Burden, R. L., \& Faires, J. D. (2011). Numerical Analysis. Boston: Brooks/Cole.

Busyairi, A., \& Zuhdi, M. (2020). Profil Miskonsepsi Mahasiswa Calon Guru Fisika Ditinjau dari Berbagai Representasi pada Materi Gerak Lurus dan Gerak Parabola. Jurnal Pendidikan Fisika dan Teknologi, 6(1), 90-98.

Chapra, S. C. (2012). Applied Numerical Methods with MATLAB for Engineers and Scientists. New York: McGraw-Hill.

Chapra, S. C., \& Canale, R. P. (2010). Numerical Methods for Engineers. Boston: McGraw-Hill Higher Education.

Herlinawati, E. (2019). Metode PNSR pada Interpolasi Gaussian. FIBONACCI: Jurnal Pendidikan Matematika dan Matematika, 5(1), 65-70.

Nurullaeli, N. (2020). Media Analisis Rangkaian Listrik Menggunakan Pendekatan Numerik GaussJordan, Gauss-Seidel, dan Cramer. Navigation Physics: Journal of Physics Education, 2(1), 1-8.

Prihatini, S., Handayani, W., \& Agustina, R. D. (2017). Identifikasi Faktor Perpindahan Terhadap Waktu yang Berpengaruh pada Kinematika Gerak Lurus Beraturan (GLB) dan Gerak Lurus Berubah Beraturan (GLBB). Journal of Teaching and Learning Physics, 2(2), 13-20. 